\title{
Correction to: Switch-on effect on conformation-specific arylamine-DNA adduct by cyclometalated Ir(III) complexes
}

\author{
David Dayanidhi Paul Elisa ${ }^{1,2} \cdot$ Vaidyanathan Vaidyanathan Ganesan ${ }^{1,2}$ (])
}

Published online: 14 August 2021

(c) Society for Biological Inorganic Chemistry (SBIC) 2021

\section{Correction to: \\ JBIC Journal of Biological Inorganic Chemistry (2020) 25:305-310 \\ https://doi.org/10.1007/s00775-020-01762-7}

In the original article, the affiliation of both the authors are published incorrectly. The affiliations are as given below:

David Dayanidhi Paul Elisa ${ }^{1,2}$. Vaidyanathan Vaidyanathan Ganesan ${ }^{1,2}$

${ }^{1}$ Advanced Materials Laboratory, CSIR-Central Leather Research Institute, Adyar, Chennai 600 020, India

\author{
${ }^{2}$ Academy of Scientific and Innovative Research (AcSIR), \\ Ghaziabad 201002, India \\ The original article has been corrected.
}

Publisher's Note Springer Nature remains neutral with regard to jurisdictional claims in published maps and institutional affiliations.

The original article can be found online at https://doi.org/10.1007/ s00775-020-01762-7.

Vaidyanathan Vaidyanathan Ganesan

vaidyanathan@clri.res.in

1 Advanced Materials Laboratory, CSIR-Central Leather Research Institute, Adyar, Chennai 600 020, India

2 Academy of Scientific and Innovative Research (AcSIR), Ghaziabad 201002, India 